\title{
Audit from preschool developmental surveillance of vision, hearing, and language referrals
}

\author{
R J Rona, A Reynolds, M Allsop, R W Morris, M Morgan, S Mandalia
}

\begin{abstract}
Referrals from preschool medical examinations were followed up for two years to assess attendance rate, waiting time for appointment, appropriateness of the referral, the diagnosis and management of the condition. Altogether 184 children were referrals for ophthalmology, 285 for audiology, and 195 for speech therapy. The median waiting time for an appointment was $\mathbf{4 6}$ days in ophthalmology, 175 days in audiology, and 83 days in speech therapy. The poorest attendance rate was identified in speech therapy (75\%). Approximately $60 \%$ of examined children had a justified referral to ophthalmology and $20 \%$ had a clear defect. Over half the children in audiology $(55 \%)$ had an altered impedance or hearing impairment. Of those with a hearing problem kept under review only half improved spontaneously. In speech therapy $80 \%$ of those assessed had a language problem. Many health problems were detected for which parents were unaware"or did not use the service. Parental awareness alone will not uncover the sizable level of lingual and sensorial problems in inner city areas. This audit identified specific deficiencies in the provision of services and a number of organisational changes are suggested to improve their effectiveness.
\end{abstract}

The joint working party on child health surveillance was sceptical of the effectiveness of many of the scheduled prescribed examinations in Britain and recommended research to evaluate the current components of the programme. ${ }^{1}$ The group was particularly critical of the assessment of squint by non-specialised personnel, visual acuity before school age, universal hearing screening after 10 months until school entry, and systematic assessment of language problems. In West Lambeth Health Authority an audit programme was carried out to assess whether the child examination schedule provided by clinics was operating efficiently. We were concerned to describe the actions which took place after a child was identified as having a sight, hearing, or language problem. Areas of ascertainment were the level of attendance to the specialist services, waiting time for appointment, the appropriateness of the referral, the diagnosis, and treatment of the referred children and the compliance with the prescribed treatment. No formal audit of these services has been carried out previously in Britain. The study should be relevant to health districts with multiethnic inner city area characteristics.
Subjects and methods

All the children aged under 4.5 years of age referred to speech therapy, audiology, or ophthalmology as a result of a scheduled examination were flagged and followed up for a two year period from August 1986. A general information document was completed by the referring clinical medical officer or health visitor and three specific documents relating to each specialty were designed to be completed by the research assistant (AR) based on information obtained from the notes and directly from the specialists. The data were recorded on a precoded form for each child at six, 12, and 24 months after referral or at discharge if this occurred before the follow up dates.

The general information document based on the examination by the clinical medical officer or health visitor recorded date of birth and sex, area of concern, specialty to which the child was referred, and whether the referral was initiated by the doctor or health visitor. The clinical medical officers used scheduled examination tests for assessment. For hearing they used the distraction test at 7 months, the Stycar 6 toy test at age 2 years, and the Stycar 7 toy test at age 3.5 years. The receptive and expressive language was examined using a modification of the tests used in the Hounslow study ${ }^{2}$ and approved by Reynell. Vision binocularity was assessed with the corneal reflection test, cover test, and eye movement at each examination and Stycar 5 letter test at 3.5 years. (This test is known to be insensitive to amblyopia so the recently developed Sonksen-Silver linear test for $\mathbf{3} \mathrm{m}$ is used now.) All the clinical medical officers have undergone in service training, but the techniques of screening were not systematically checked during the study period.

Information from the specialists to whom the children were referred was recorded for the following items for each specialty. (1) At first assessment the attendance and, if appropriate, reasons for non-attendance, date of initial assessment, findings of initial assessment, and management plan. (2) At the second and third assessment details of most recent examination and type of management carried out since the last follow up, for example, surgery, visual aids, treatment, etc. For audiology, hearing impairment and impedance were assessed over the two year period. Language, mouth, voice, articulation, and fluency problems were assessed. In addition the Reynell test was used to measure language comprehension and expressive language. The number of treatment sessions with the speech therapist was recorded. The ophthalmology information on binocularity, refractive 
problems, vision acuity with corrective aids, if available, amblyopia, and other pathology were recorded.

We aimed to collect at least 180 children in each specialty. Data were collected for seven months in audiology (which had the highest referral rate), eight months in ophthalmology, and 11 months in speech therapy.

\section{Results}

Table 1 gives the age on referral, date, and sex distribution of children referred to three specialties. Altogether 184 children were referred to ophthalmology, 285 to audiology, and 195 to speech therapy. Appreciably more boys were referred to speech therapy than girls. In ophthalmology proportionally more children were referred who were under 1 and over 3 years old. In audiology proportionally more children were referred in the younger age groups whereas for speech therapy, with the exception of one boy, specialist opinion was required after the child's first year of life. Multiple referrals in the three specialties of interest were detected for 38 children referred to audiology and speech therapy, 13 referred to audiology and ophthalmology, seven referred to ophthalmology and speech therapy, and four to the three specialties. The referral rates for the three specialties were approximately $10 \%$ in audiology, $6 \%$ in ophthalmology, and $4 \%$ in speech therapy. The referral rate in speech therapy may have been underestimated because unlike the other two specialties there was a lack of a centralised administrative system making cross checking of referrals difficult.

Figure 1 shows the main process events of the referred children during the two years follow up. Compliance, defined as attending the specialised clinic at least once, was $79 \cdot 9 \%, 75 \cdot 1 \%$, and $63.6 \%$ of children referred to ophthalmology, audiology, and speech therapy respectively. Some children had predicted reasons for non-attendance such as change of address, parental refusal at invitation stage, or children already undergoing assessment by the service. Between $3.3 \%$ and $5.6 \%$ of the flagged referrals were not traced in the specialised clinics. The true non-attendance was $15 \cdot 2 \%, 17 \cdot 2 \%$, and $25 \cdot 1 \%$ in ophthalmology, audiology, and speech therapy respectively. Approximately a quarter of all referred children were discharged in ophthalmology and audiology after first assessment and the equivalent percentage in speech therapy was $10.8 \%$. In addition, around $15 \%$ of the children in ophthalmology, $18 \%$ in speech therapy, and $8 \%$ in audiology did not attend the

Table 1 Age and sex distribution of referred children by specialty referred to. Results are number (\%)

\begin{tabular}{|c|c|c|c|c|c|c|}
\hline \multirow{2}{*}{$\begin{array}{l}\text { Age } \\
\text { (years) }\end{array}$} & \multicolumn{2}{|c|}{ Ophthalmology } & \multicolumn{2}{|l|}{ Audiology } & \multicolumn{2}{|c|}{ Speech therapy } \\
\hline & Boys & Girls & Boys & Girls & Boys & Girls \\
\hline $\begin{array}{l}<1 \\
1-2 \cdot 9 \\
\geqslant 3 \\
\text { Total }\end{array}$ & $\begin{array}{l}31(37 \cdot 3) \\
18(21 \cdot 7) \\
34(41 \cdot 0) \\
83(100 \cdot 0)\end{array}$ & $\begin{array}{c}45(44 \cdot 6) \\
23(22 \cdot 8) \\
33(32 \cdot 7) \\
101(100 \cdot 0)\end{array}$ & $\begin{array}{c}60(38 \cdot 7) \\
69(44 \cdot 5) \\
26(16 \cdot 8) \\
155(100 \cdot 0)\end{array}$ & $\begin{array}{c}53(40 \cdot 8) \\
50(38 \cdot 5) \\
27(20 \cdot 8) \\
130(100 \cdot 0)\end{array}$ & $\begin{array}{c}1(0 \cdot 8) \\
66(54 \cdot 1) \\
55(45 \cdot 1) \\
122(100 \cdot 0)\end{array}$ & $\begin{array}{l}0 \\
50(68 \cdot 5) \\
23(31 \cdot 5) \\
73(100 \cdot 0)\end{array}$ \\
\hline
\end{tabular}

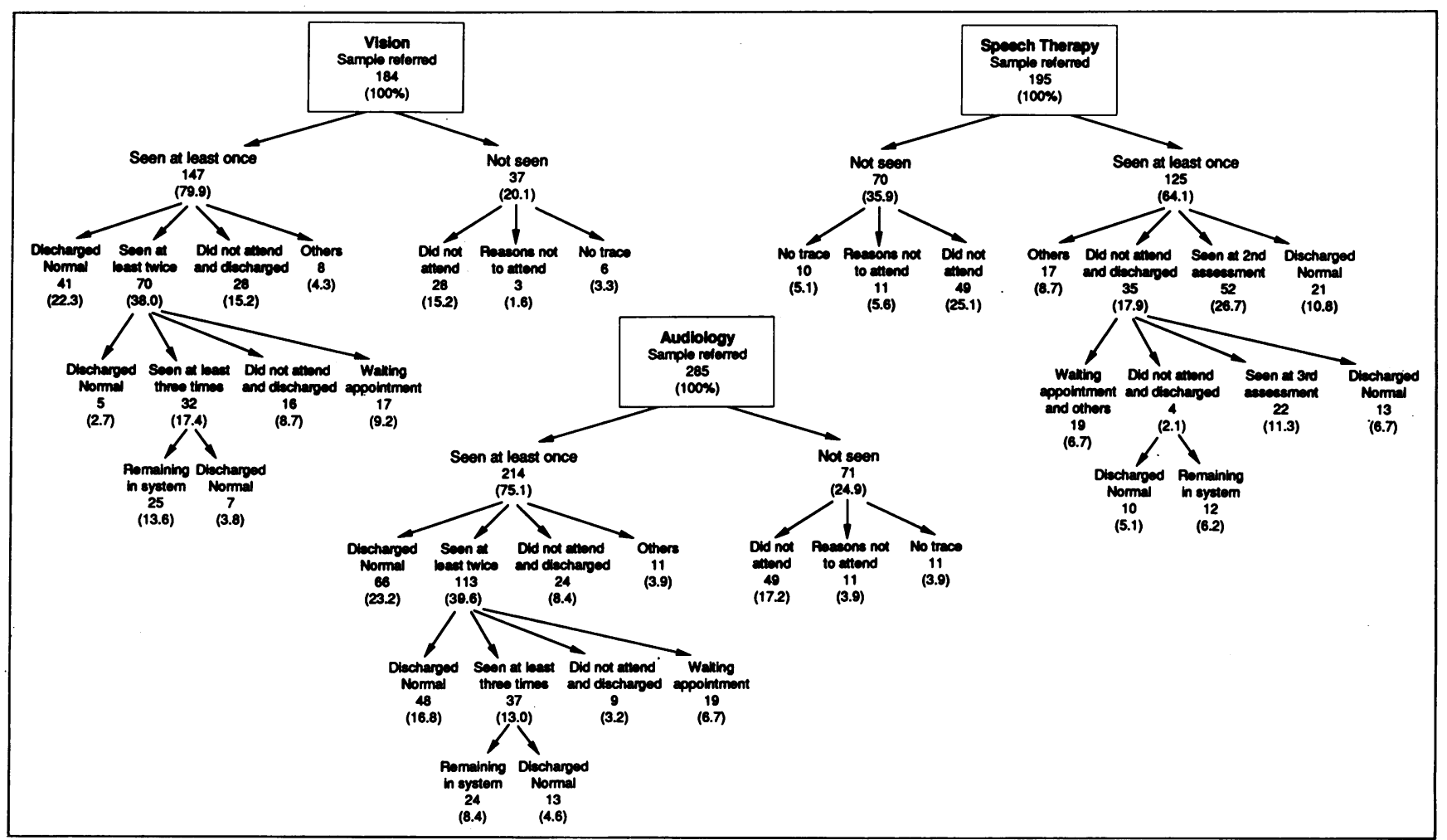

Figure 1 Compliance with specialist clinic and process events of referred children. 
specialised clinic after first assessment. At the end of the two years' follow up, approximately $42(22 \cdot 8 \%)$ children were still in this system in ophthalmology and $43(15 \cdot 1 \%)$ in audiology and in speech therapy there were approximately 25 $(12 \cdot 9 \%)$ children.

The waiting time for first assessment varied by speciality. For vision the mean time was $62 \cdot 7$ days (median 46 days), for audiology a mean of 179.8 days (median 175 days), and for speech therapy a mean of $88 \cdot 5$ days (median 83 days).

\section{OPHTHALMOLOGY}

Table 2 gives the initial assessment of diagnostic events by age in ophthalmology. There were 66 children for whom no problem has yet been identified. For most children aged less than age 2 years visual acuity was not assessed. Strabismus was detected in 13 children and most of them had a non-paralytic squint. In another 45 children no squint was found but there were reasons for the clinical medical officers to suspect a squint (either pseudosquint or family history). Two children were diagnosed at a later

Table 2 Diagnostic events of children referred to ophthalmology by age

\begin{tabular}{|c|c|c|c|c|}
\hline & \multicolumn{3}{|c|}{ Age (years) } & \multirow[t]{2}{*}{ All } \\
\hline & 0.0 .9 & $1-2.9$ & $3-4.9$ & \\
\hline $\begin{array}{l}\text { Binocularity: } \\
\text { Non-paralytic } \\
\text { Accomodative } \\
\text { Pseudosquint } \\
\text { Family history } \\
\text { Refractive problem alone }\end{array}$ & $\begin{array}{r}4 \\
1 \\
21 \\
10 \\
6\end{array}$ & $\begin{array}{r}3 \\
1 \\
8 \\
5\end{array}$ & $\begin{array}{r}2 \\
2 \\
2 \\
4 \\
12\end{array}$ & $\begin{array}{r}9 \\
4 \\
31 \\
14 \\
23\end{array}$ \\
\hline $\begin{array}{l}\text { Visual acuity: } \\
\text { Bilateral 6/9 } \\
\text { One line difference } \\
\text { Two lines difference } \\
\text { Bilateral } 6 / 12 \\
\text { Unknown } \\
\text { No abnormal findings }\end{array}$ & $\begin{array}{l}\text { N/A } \\
\text { N/A } \\
\text { N/A } \\
\text { N/A } \\
2 \\
24\end{array}$ & $\begin{array}{r}3 \\
2 \\
1 \\
1 \\
14\end{array}$ & $\begin{array}{r}10 \\
2 \\
2 \\
2 \\
28\end{array}$ & $\begin{array}{r}13 \\
4 \\
3 \\
2 \\
3 \\
66\end{array}$ \\
\hline
\end{tabular}

Table 3 Number of children with at least one ophthalmic problem in the initial assessment and whether a treatment was prescribed

\begin{tabular}{lcc}
\hline & $\begin{array}{l}\text { No of } \\
\text { children }\end{array}$ & $\begin{array}{l}\text { No } \\
\text { treated }\end{array}$ \\
\hline Squint only & 6 & 1 \\
Refraction problem only & 9 & 7 \\
Squint and refraction defects & 6 & 4 \\
Refraction and visual acuity defects & 7 & 7 \\
Squint, refraction, and visual acuity defects & 1 & 1 \\
Total & 29 & 20 \\
\hline
\end{tabular}

stage as having a non-paralytic squint and another child initially said to have an accommodative squint had his diagnosis changed to normal. Twenty three children had a refractive problem, seven had hypermetropia, six had hypermetropia astrigmatism, three myopic, five myopic astigmatic, and two were astigmatic. Visual acuity defects were detected in nine children including one line difference in visual acuity between right and left eye but excluding a bilateral visual acuity of 6/9. At a later assessment another three children had developed decreased visual acuities that were not detected initially. Thus the referral was justifiable in $55 \%$ of the children. Table 3 gives the number of children with at least one ophthalmic problem and the number of children in each group treated. Of the 29 children with an ophthalmic problem 20 were given treatment. Most children with a refraction and visual acuity problem were treated but five out of six children with squint only were left under observation. Of the children with a refractive problem 14 were treated with glasses and four with occlusion and glasses.

There seemed to be no consistency in the discharge policy of the ophthalmology clinic. For example 10 of the 31 children with pseudosquint were discharged immediately and seven were discharged after a second assessment but 12 of the children remained in the system until the end of the study. The same phenomenon was observed for mild visual problems (6/9) and at risk of squint. Of those children given treatment compliance was good in 14, poor in four children, and unknown in two children. Outcome assessment of treatment was not possible given the small number of children in each diagnostic category.

\section{AUDIOLOGY}

Table 4 gives information about initial assessment and action taken in the audiology clinic. In general children referred from audiology to the ear, nose, and throat department or the general practitioner had a flat impedance trace and a moderate or mild hearing impairment. On the other hand most children discharged after first assessment had normal hearing and impedance tests, only five were discharged with a mild hearing impairment, and one with a flat impedance test. In the group who continued under review there was a large percentage of children with apparently similar results to those referred to ear, nose, and throat or the general practitioner. Twenty children with a flat impedance had either a moderate or mild hearing

Table 4 Tests results and action taken after initial assessment in audiology clinic (hearing loss graded severe, moderate, mild, normal, based on worse ear)

\begin{tabular}{|c|c|c|c|c|c|c|c|c|c|c|c|c|c|c|c|c|c|c|}
\hline \multirow{3}{*}{$\begin{array}{l}\text { Action } \\
\text { after } \\
\text { first } \\
\text { assessment }\end{array}$} & \multicolumn{18}{|c|}{ Impedance } \\
\hline & \multicolumn{5}{|l|}{ Flat } & \multicolumn{4}{|c|}{ Slight alteration } & \multicolumn{4}{|l|}{ Normal } & \multicolumn{4}{|l|}{ Not tested } & \multirow[b]{2}{*}{ Total } \\
\hline & Severe & Moderate & Mild & Normal & $\begin{array}{l}\text { Not } \\
\text { tested }\end{array}$ & Moderate & Mild & Normal & $\begin{array}{l}\text { Not } \\
\text { eested }\end{array}$ & Moderate & Mild & Normal & $\begin{array}{l}\text { Not } \\
\text { tested }\end{array}$ & Moderate & Mild & Normal & $\begin{array}{l}\text { Not } \\
\text { tested }\end{array}$ & \\
\hline $\begin{array}{l}\text { Ear, nose, } \\
\text { and throat } \\
\text { General }\end{array}$ & - & 4 & 5 & - & 4 & - & 1 & - & - & - & - & - & - & - & - & - & - & 14 \\
\hline $\begin{array}{l}\text { General } \\
\text { practitioner } \\
\text { Other }\end{array}$ & $\overline{1}$ & 6 & 16 & $\bar{z}$ & $\begin{array}{l}1 \\
2\end{array}$ & $=$ & $\begin{array}{l}3 \\
1\end{array}$ & $\bar{z}$ & $\frac{1}{3}$ & $=$ & $\bar{z}$ & $\overline{1}$ & $\overline{3}$ & $\bar{z}$ & $\bar{z}$ & $\bar{z}$ & 二 & $\begin{array}{l}27 \\
11\end{array}$ \\
\hline $\begin{array}{l}\text { Under review } \\
\text { Discharged }\end{array}$ & $=$ & $\overline{2}$ & $\overline{18}$ & 1 & $\underline{4}$ & $\frac{3}{-}$ & $\begin{array}{r}26 \\
1\end{array}$ & $\begin{array}{l}4 \\
7\end{array}$ & $\begin{array}{l}7 \\
6\end{array}$ & -5 & $\begin{array}{r}19 \\
3\end{array}$ & $\begin{array}{r}1 \\
20\end{array}$ & $\begin{array}{r}5 \\
24\end{array}$ & $\overline{-}$ & $\begin{array}{l}1 \\
1\end{array}$ & $\overline{3}$ & $\overline{1}$ & $\begin{array}{l}96 \\
66\end{array}$ \\
\hline
\end{tabular}


defect and another 29 had a hearing impairment and slightly abnormal impedance. The action decided was not related to hearing impairment being bilateral or unilateral as most children had bilateral hearing impairment. Too few children required referral to sensorineural evaluation for helpful analysis.

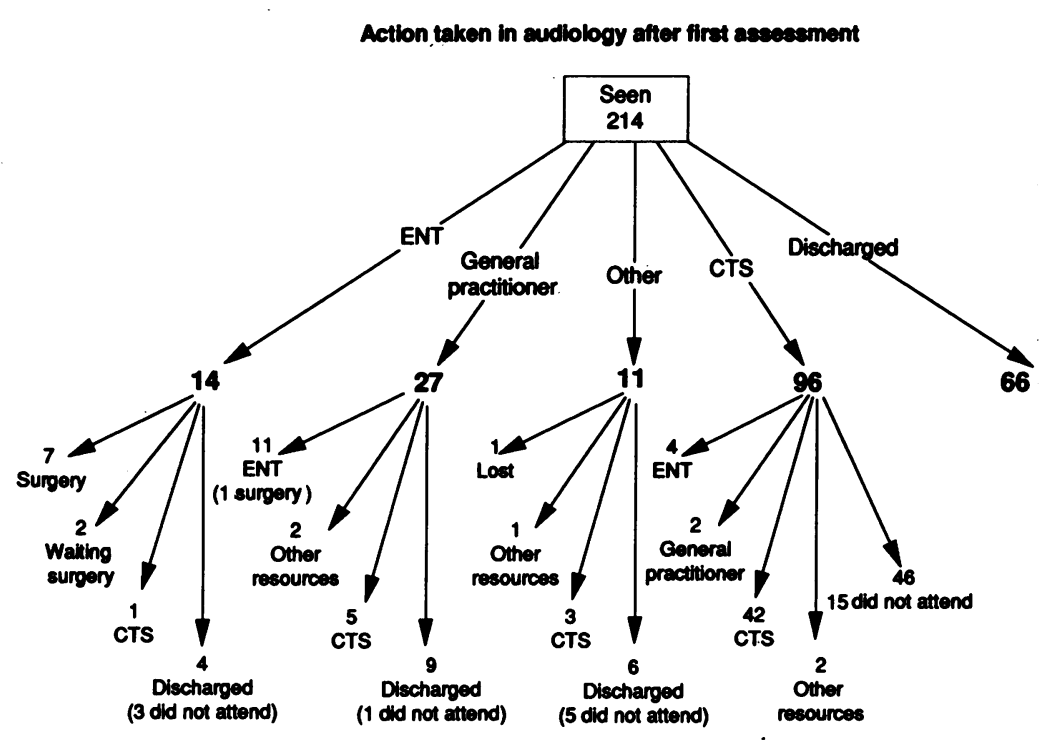

Figure 2 Action taken in audiology after first assessment. CTS=continued to see; $E N T=e a r$, nose, and throat department.

Table 5 Referral to speech therapy according to number of language problems

\begin{tabular}{|c|c|c|c|c|c|c|}
\hline & \multicolumn{4}{|c|}{ Age at referral (years) } & \multicolumn{2}{|l|}{ Total } \\
\hline & \multicolumn{2}{|c|}{$1 \cdot 0-2 \cdot 9$} & \multicolumn{2}{|c|}{$3 \cdot 0-4 \cdot 9$} & \multirow[b]{2}{*}{ Boys } & \multirow[b]{2}{*}{ Girls } \\
\hline & Boys & Girls & Boys & Girls & & \\
\hline $\begin{array}{l}\text { No problem } \\
\text { One problem: }\end{array}$ & 4 & 6 & 5 & 4 & 9 & 10 \\
\hline $\begin{array}{l}\text { Moderate or severe } \\
\text { Mild }\end{array}$ & $\begin{array}{l}4 \\
4\end{array}$ & $\begin{array}{l}1 \\
4\end{array}$ & $\begin{array}{l}8 \\
6\end{array}$ & $\begin{array}{l}2 \\
1\end{array}$ & $\begin{array}{l}12 \\
10\end{array}$ & $\begin{array}{l}3 \\
5\end{array}$ \\
\hline $\begin{array}{l}\text { Two problems: } \\
\text { Moderate or severe } \\
\text { Mild }\end{array}$ & $\begin{array}{r}17 \\
4\end{array}$ & $\begin{array}{r}12 \\
6\end{array}$ & $\begin{array}{l}5 \\
4\end{array}$ & $\begin{array}{l}2 \\
2\end{array}$ & $\begin{array}{r}22 \\
8\end{array}$ & $\begin{array}{r}14 \\
8\end{array}$ \\
\hline $\begin{array}{l}\text { Three problems: } \\
\text { Moderate or severe } \\
\text { Mild } \\
\text { More than three }\end{array}$ & $\begin{array}{l}6 \\
1\end{array}$ & $\begin{array}{l}3 \\
1\end{array}$ & $\underline{2}$ & -4 & $\begin{array}{l}8 \\
1\end{array}$ & $\begin{array}{l}7 \\
1\end{array}$ \\
\hline $\begin{array}{l}\text { problems } \\
\text { Incomplete assessment } \\
\text { or not known }\end{array}$ & - & 1 & - & - & 一 & 3 \\
\hline Total & 43 & 37 & 30 & 15 & 73 & 52 \\
\hline
\end{tabular}

Figure 2 shows a flow chart of eventual action in relation to initial decision. Half of the children sent to the ear, nose, and throat department had surgery by the end of the follow up period. Approximately $\mathbf{4 0 \%}$ of the children sent to the general practitioner were subsequently referred to the ear, nose, and throat department. Of those children who remained under review after initial assessment half of them were discharged or did not attend subsequent appointments, $6 \%$ were sent to the ear, nose, and throat department or their general practitioners, and $44 \%$ were still under review at the end of the follow up period. Most of the children discharged in the second or third assessment had a normal hearing and impedance test. The group under review is of interest because it provides an overview of the natural history in a two year period of hearing impairment or flat impedance of untreated children. Approximately half of these children improved spontaneously between two successive assessments. The children sent to general practitioners had a lower rate of recovery as only six out of $23 \mathrm{had}$ a normal impedance and eight out of 24 had normal hearing in the follow up assessment.

\section{SPEECH THERAPY}

Table 5 shows the distribution of referred children according to age and the number and severity of language problems. A large percentage of the referrals were of children under 3 years. Most assessed children were diagnosed as having a language problem $(80 \%)$ and of these most had at least a moderate problem according to the speech therapist. Altogether 108 problems were detected in boys and 77 in girls. In table 6 the children are distributed according to the most severe language problem and the number of sessions the children attended speech therapy during the follow up period. Only 23 children had 11 or more sessions of speech therapy. The main reason for a low attendance rate (10 or fewer sessions) was low compliance. Improvement with treatment was observed in half the children who had problems. Unfortunately the data on outcome were based on speech therapists' subjective assessment as results of the Reynell test were rarely available.

Table 6 Distribution of children by most severe language problem and number of speech therapy sessions in follow up period (excluding first assessment) of those for whom treatment was planned

\begin{tabular}{|c|c|c|c|c|c|c|c|c|}
\hline & \multicolumn{6}{|c|}{ No of sessions } & \multirow[t]{2}{*}{ Others*t } & \multirow[t]{2}{*}{ Total } \\
\hline & $1-5^{*}$ & $6-10^{*}$ & $11-15$ & $16-20$ & $21-30$ & $\geqslant 30$ & & \\
\hline $\begin{array}{l}\text { Articulation: } \\
\text { Severe } \\
\text { Moderate } \\
\text { Mild }\end{array}$ & $\overline{1}$ & $\overline{2}$ & $\frac{5}{3}$ & $\frac{1}{1}$ & $\frac{1}{1}$ & $\frac{1}{2}$ & $\begin{array}{r}1 \\
-3 \\
-\end{array}$ & $\begin{array}{r}3 \\
11 \\
1\end{array}$ \\
\hline $\begin{array}{l}\text { Expression and comprehension: } \\
\text { Severe } \\
\text { Moderate } \\
\text { Mild }\end{array}$ & $\begin{array}{l}1 \\
2 \\
2\end{array}$ & $\begin{array}{l}3 \\
4 \\
3\end{array}$ & $\overline{4}$ & $\begin{array}{l}- \\
3 \\
1\end{array}$ & $\frac{1}{-}$ & $\begin{array}{l}1 \\
1 \\
1\end{array}$ & $\begin{array}{r}3 \\
15 \\
-\end{array}$ & $\begin{array}{r}99 \\
29 \\
7\end{array}$ \\
\hline $\begin{array}{l}\text { Two problems of similar severity: } \\
\text { Severe } \\
\text { Moderate } \\
\text { Mild }\end{array}$ & $\frac{1}{-}$ & $\begin{array}{l}1 \\
-\end{array}$ & $\bar{z}$ & $\bar{z}$ & $\overline{1}$ & $\frac{2}{-}$ & $\frac{1}{-}$ & $\begin{array}{l}5 \\
2 \\
1\end{array}$ \\
\hline Total & 8 & 14 & 7 & 5 & 5 & 6 & 23 & 68 \\
\hline
\end{tabular}

*Ten children attended fewer than 10 sessions: because did not keep appointment $(n=6)$, were transferred $(n=1)$, went to a language unit $(n=1)$, needed interpreter $(n=1)$, or had assessment of specific needs $(n=1)$. tImmediately transferred, moved to another district, or non-compliance. 
Discussion

At a time of great interest in medical audit ${ }^{13}$ this paper highlights a number of organisational and clinical issues related to the provision of an integrated screening system to detect and manage preschool children with a possible vision, hearing, or language problem. From an organisational viewpoint helpful information was obtained with respect to attendance, children referred but not seen at the specialist clinic, and time waiting for initial assessment. From a clinical perspective data were available about rate of justified referrals, changes in diagnosis over time, treatment compliance, and discharge policies. Valuable information was available on spontaneous recovery of children who were under review during the period of observation.

In this paper parents' concern about their child's referral to the specialist service was not assessed directly. However, a measure of their concern would be given by the attendance at the clinics. In this study both initial non-attendance and non-attendance after having contacted the clinic were assessed. Poor attendance at the specialist service was a serious problem in speech therapy where $25 \cdot 1 \%$ of the children did not attend after three appointments were sent to the parents. The rate of non-compliance in speech therapy cannot be explained by change of address or general apathy because the noncompliance rate was well above that of the other specialties. The high non-attendance rate anteceded any direct knowledge of the speech therapy service. The parents may perceive this service as more dispensable than the ophthalmology and audiology clinics. Clinical medical officers, general practitioners, and health visitors should be prepared to spend time explaining to parents the reason and potential benefits for the child being referred to speech therapy. The advice to parents should be very carefully worded because parents may believe that language delay is synonymous with mental retardation. An added difficulty for the practitioners is that some of these parents have poorly developed language themselves.

Non-compliance after having contacted the clinic was high in ophthalmology and speech therapy. In ophthalmology the majority of those who did not comply after initial assessment were normal, although a substantial number had pseudosquint or family history of squint. Among those who had at least two assessments a large percentage were diagnosed with a vision deficit. Low compliance in children followed up by the orthoptist has been reported previously. ${ }^{4}$ In the group with only initial assessment parents may have felt sufficiently reassured with the results of this examination whereas the orthoptist or ophthalmologist may have wished to undertake a second check. In the second group parents may have decided to stop coming after a child was diagnosed with a defect but not given a treatment or given a treatment that the child found unpleasant. It is possible that many of these parents looked for a second opinion elsewhere.

In speech therapy there was no clear association between severity of findings at initial assessment and rate of non-attendance. Severity of problems were similar for those attending only the first assessment and those attending more assessments. However, most of those attending more than 10 sessions of speech therapy had a moderate or severe language problem. Possible reasons explaining the very large percentage of non-compliance after initial contact are the laborious nature of the specialty that demands weekly visits, the existence of two waiting lists, one for initial assessment and the other for treatment, and the high turnover of these therapists during the period of observation. A possible solution to the low compliance would be to arrange with parents an acceptable length of treatment time. This is an area that needs close monitoring because low compliance will reduce the potential benefit of speech therapy.

There were long delays between referral and initial assessment in the three specialties. At our first six months of assessment almost all the children referred to speech therapy and ophthalmology had been seen. In contrast, only half the children referred to audiology had been seen in the first six months. Despite this, audiology had the highest compliance rate after first assessment. This would indicate that parents were worried by the possibility of a hearing problem in their child.

The initial assessment of referred children indicated that a very large percentage of them had a problem necessitating diagnosis and management in terms of treatment and advice. A conductive defect and, rarely, a sensorineural problem was suspected in $60 \%$ of the children referred to audiology. The yield of problems in ophthalmology was only $20 \%$, but for a further $31 \%$ a more specialised staff was required to exclude a squint. In speech therapy very few children were diagnosed as not having a language problem, but the assessments were not based on a widely used item derived test.

The very high detection rate for conductive problems was unexpected given the intermittent nature of the problem and the very long waiting time for an appointment in this specialty. All the information in this study indicates that a large percentage of the children had a persistent defect. This is illustrated by the high percentage of children referred to the ear, nose, and throat department who were operated on, the high percentage referred to the general practitioner for medical treatment who were eventually referred to the ear, nose, and throat department, and by the persistence of an impaired impedance and/or hearing loss in the large group under review. As complications, inconvenience, and cost of surgery are not negligible ${ }^{5}$ it is appropriate to observe these children with middle ear effusion until the persistence of the problem is well documented. In this study children with apparently similar results in the hearing assessment were, in some cases, sent immediately to the ear, nose, and throat department, sometimes referred to the general practitioner, and others kept under review. The variety of approaches could be explained by differences in the history of the hearing disorder such as number of episodes, hearing infection, language delay, and duration of the disorder. It 
is clear that for the severe and persistent conductive defect lack of intervention will result in significant delay of language development. ${ }^{6}$ However, the relation between milder forms of hearing impairment or unilateral impairment with language development remain unproved and therefore urgent surgery may not be warranted on those grounds. ${ }^{5}$ After the study period the audiology clinic changed policy and children are no longer sent to the general practitioner for medical treatment. This new approach is supported by our results showing that very few children improved their audiology problems after attending the general practitioner.

The ophthalmology examination uncovered a large number of refractive problems. Many children with refractive problems also had squint and/or low visual acuity. The design of the study does not allow us to contribute to the discussion of the relation between refractive problems, squint, and amblyopia. ${ }^{7}$ Many of the visual acuity problems were minimal: only nine children had a visual acuity defect in the initial assessment. A further 12 children had bilateral $6 / 9$ vision and were not defined as having a problem. These children were not given treatment. The great majority of children with tested low acuity were older than 3 years at the time of screening. If this low acuity was associated with a refraction problem, glasses only or glasses and occlusion were prescribed. Approximately $75 \%$ of treated children had good compliance during the period of observation. With the small number of children with refraction problems and defective acuity it is not possible to contribute to the discussion as to whether screening at 3.5 years is dispensable or whether the condition deteriorates if treatment is not provided. ${ }^{7}$

The assessment of the work of speech therapy would indicate that a large number of children improved during the period of treatment. There are two caveats to this finding. Firstly, that no quantitative and objective assessments were available for most children in the initial and final assessment. Secondly, that it is difficult to distinguish in this group those children that have a below normal language standard, but who will catch up spontaneously, from those who will have a persistent language delay. ${ }^{8}$ There are several reasons why the Reynell test may not be frequently used by the speech therapist. In the initial assessment the Reynell test may not be suitable because the child's attention span is insufficiently developed and many therapists feel that at either end of the assessment range the test is not satisfactory. In the posttreatment assessments parents may refuse further sessions, or appointments are not kept, and some patients are placed on review. Some may recover spontaneously in this period and fail to attend for the final assessment to confirm improvement.

This audit of vision, hearing, and language referrals identified the very large number of children with a sensory or language problem in an inner city area from whom detection, reassurance, close follow up, or treatment were required. A very large number of conductive hearing problems did not seem to recede spontaneously over time. From this perspective it is difficult to agree with a recommendation that parental awareness alone ${ }^{1}$ would uncover the sizable level of appropriate referrals identified by the current formal clinical examination. We fear that the children of the less articulate and knowledgeable segment of the community will suffer as a consequence of such a policy. However, a number of organisational problems with implications for the efficiency of the service were identified. A particular pattern for speech therapy was the low compliance in terms of attendance at the specialist clinic. This may be due to parents placing a low value on this service, suggesting that rates of attendance may be increased through explaining more fully the aims and pattern of treatment to parents. There was also a considerable gap between initial assessment and an appointment for specialist audiology services that might be reduced through better waiting list management. Other findings raise questions requiring further research. For example in ophthalmology there appeared to be considerable variability in the treatment of squint which raises questions of the relative outcomes achieved. Similary, there are questions of the effectiveness of speech therapy.

We thank everybody concerned in the community preschool health services in the West Lambeth Health Authority and in particular Dr L Fowle, Ms D Avery, Mrs P Wood, Dr K Papas, and Ms L Humber. We also thank Professor $W W$ Holland for his encouragement. The study was funded by a grant from the South East Thames Regional Health Authority.

1 Hall DMB, ed. Health for all children. A programme for child health surveillance. Oxford: Oxford University Press, 1989.

2 Zinkin PM, Cox CA. Child health clinics and inverse care laws: evidence from a longitudinal study of 1878 pre-school children. $B M F$ 1976;ii:411-3.

3 Secretaries of State for Health, Wales, Scotland and Northern Ireland. Working for patients. London: HMSO, 1989.

4 Hall SM, Pugh AG, Hall DMB. Vision screening in the under 5s. BMY 1982;285:1086-8.

5 Paradise JL. Otitis media during early life: how hazardous to development? A critical review of the evidence. Pediatrics 1981;68:869-73.

6 Hall DMB, Hill P. When does secretory otitis media affect language development? Arch Dis Child 1986;61:42-7.

7 Ingram RM, Holland WW, Walker C, Wilson JM, Arnold PE, Dolly S. Screening per visual defect in preschool chilPE, Dolly S. Screening per visual defect
dren. $\mathrm{Br} \mathcal{f}$ Ophthalmol 1986;70:16-21.

8 Hall $D$. Delayed speech in children. Usually normal variation, but may be a 'specific speech and language disorder'. $B M \mathcal{F}$ 1989;287:1281-2. 